\title{
Actual Aspects of Medical and Social Expertise and Rehabilitation of Persons Injured at Work
}

\section{Bodrova Rezeda Akhmetovna ${ }^{1}$, Ishteryakova Olga Alexandrovna ${ }^{2 *}$, Iksanov Haidar Vazikhovich ${ }^{1}$ and Gilyazov Kamil Robertovich ${ }^{3}$}

${ }^{1}$ Kazan State Medical Academy - branch of the Russian Medical Academy of Continuing Professional Education of the Ministry of Health of the Russian

Federation, Kazan, Republic of Tatarstan, Russian Federation

${ }^{2}$ FSBEI HE "Kazan State Medical University" of the Ministry of Health of the Russian Federation, Kazan, Republic of Tatarstan, Russian Federation

${ }^{3}$ Kazan State Medical Academy - Branch of the Russian Medical Academy of Continuing Professional Education of the Ministry of Health of the Russian Federation, Kazan, Republic of Tatarstan, Russian Federation

*Corresponding Author: Ishteryakova Olga Aleksandrovna, Associate Professor of the Department of Hygiene and Occupational Medicine, Kazan State Medical University, Ministry of Health of the Russian Federation, Kazan, Republic of Tatarstan, Russian Federation.
Received: April 22, 2021

Published: June 12, 2021

(C) All rights are reserved by Bodrova Rezeda Akhmetovna., et al.

\section{Abstract}

Occupational diseases (OD) that develop as a result of exposure of the employee to hazardous industrial factors, and accidents at work (industrial injuries) lead to disability and, as a result, to the need for material compensation for damage to health. According to the conclusion of the bureau of medical and social expertise, persons with occupational diseases and the consequences of accidents at work, accompanied by loss of occupational ability of work, including the definition of a disability group, are assigned insurance payments from the budget of the Social Insurance Fund of the Russian Federation. Considering the necessity of compensation payments, disability due to occupational diseases and the consequences of industrial accidents is of great social importance. In the past 10 years, the rate of disability from OD in Tatarstan was $0.06-0.10$ per 10,000 working-age population. At the same time, rather high rates of late diagnosis of OD were noted, indicating the low quality of periodic medical examinations. As a result, a significant proportion of patients undergo medical and social expertise (MSE) immediately after establishing a connection between the disease and the profession. In the structure of expenditures of the Social Insurance Fund (SIF) in the first place - payment of compensation for lost earnings ( $87-90 \%$ of funds). $10-13 \%$ is spent on the implementation of preventive measures and rehabilitation. The priority place in the rehabilitation of persons injured at work belongs to the sanatorium-resort treatment (ST). With OD, rehabilitation at the expense of the SIF is currently carried out in the presence of persistent disability (moderate and pronounced manifestations of OD) after the conclusion of the MSE. For people who have suffered from severe accidents at work, immediately after the onset of industrial injuries, an early comprehensive rehabilitation program is implemented, including ST. In the Republic of Tatarstan, within the framework of this project, the costs of ST account for up to $44 \%$ of the funds spent on early rehabilitation. In 2015 . during the implementation of the this project, $40 \%$ of the number of severe industrial injuries ended in full recovery and restoration of working capacity; since 2017 the growth of this indicator was recorded (more than $70 \%$ at present). In order to further optimize the expert 
and rehabilitation section of the work on medical care for persons injured at work, it is advisable to make appropriate changes to the existing regulatory documents and consolidate the priority of preventive measures to prevent OD and accidents at work in the distribution of social insurance funds. Improving the quality of medical support for workers with harmful factors and patients with OD will help prevent disability due to OD and save social insurance funds.

Keywords: Occupational Diseases; Industrial Injuries; Accident at Work; Medical and Social Expertise; Rehabilitation; Social Insurance

\section{Abbreviations}

OD: Occupational Diseases; MSE: Medical and Social Expertise; ST: Sanatorium Treatment; SIF: Social Insurance Fund

\section{Introduction}

Occupational diseases that develop as a result of exposure of the employee to hazardous industrial factors, and accidents at work (industrial injuries) lead to loss of occupational ability of work and, as a result, to the need for material compensation for damage to health. To assess the working capacity of patients with occupational diseases and persons with the consequences of accidents at work, to determine the need for rehabilitation, a medical and social expertise is carried out. According to the conclusion of the bureau of medical and social expertise, persons with occupational diseases and the consequences of accidents at work, accompanied by loss of occupational ability of work, including the definition of a disability group, are assigned insurance payments from the budget of the Social Insurance Fund (SIF) of the Russian Federation $[4,5]$.

In the Russian Federation, the overwhelming majority of people who are diagnosed with disability for the first time are of working age $-82 \%$. When analyzing the structure and levels of primary disability in Russia among people of working age by disease class, it was found that occupational diseases are $0.2-0.4$ per 10,000 working-age population, industrial injuries - $0.3-0.5$ per 10,000 working-age population (to the data of the Federal register of disabled people from Russian Federation). In connection with the need for compensation payments, disability due to occupational diseases and the consequences of industrial injuries is of great social importance [1].

Medical and social expertise of persons injured at work is car- ried out on the basis of an assessment of the state of health and the degree of limitation of life activity on the basis of an analysis of clinical and functional, professional, social criteria. Dynamic functional studies are needed to determine the clinical prognosis. An obligatory section of medical and social expertise is the development of a rehabilitation program for the injured at work, containing a list of rehabilitation measures for a patient with an occupational disease or the consequences of an accident at work, implemented at the expense of the SIF $[2,6]$.

\section{Purpose of the Study}

The purpose of this work is to study the features of medical and social expertise (MSE) and rehabilitation in occupational diseases and accidents at work in the Republic of Tatarstan.

\section{Materials and Methods}

The research methods were applied: analysis of medical records of the occupational pathology center and the bureau of medical and social expertise, clinical expert method, statistical method. The study was carried out using specially developed statistical maps (Ishteryakova 0., 2008), approved by the Ministry of Health of Tatarstan.

\section{Results and Discussion}

In Tatarstan, $32 \%$ of workers in various sectors of the economy have contact with hazardous industrial factors of the working environment (among them women - 31.5\%). From 17 to $23 \%$ of them work in conditions that do not meet sanitary standards. The largest number of them is found in the agro-industrial complex, automobile and aircraft construction, oil production and oil refining industries.

The proportion of recipients of insurance payments for com- 
pensation for damage to health in connection with occupational disease in Tatarstan is $47-52 \%$ of the number of those registered at the center of occupational pathology. In general, in the structure of the injured at work, the share of recipients of insurance payments from OD is $17-21 \%$ (the majority of persons with the consequences of the accident at work - 79-83\%, respectively). The largest number of insured events is registered in the $40-60$ age groups $(67 \%$ of men and $82 \%$ of women).

The analysis of nosological forms of OD during expertising at the MSE showed the predominance of respiratory pathology in patients with disabilities according to OD (55\% of patients were recognized as disabled), especially group II (65-70\% among all patients who were assigned group II disability). This is explained by the peculiarities of the clinic, the severity of the course of the pathological process, and the frequent addition of complications. Hazardous industrial factors are the main disabling factor for patients with OD of the respiratory system $(\mathrm{p}<0.001)$. The average age of disability due to OD is $(47.5 \pm 6.0)$ years.

In the past 10 years, the rate of disability from OD in Tatarstan was $0.06-0.10$ per 10,000 working-age population. At the same time, rather high rates of late diagnosis of OD were noted, indicating the low quality of periodic medical examinations. As a result, a significant proportion of patients undergo MSE immediately after establishing a connection between the disease and the occupation.

The leading role in the treatment of OD is played by rational employment and vocational rehabilitation. Medical rehabilitation for OD and accidents at work includes: drug provision, sanatorium treatment (in combination with an outpatient course of drug therapy), technical means of rehabilitation (prosthetics), for a number of diseases and injuries, social rehabilitation is relevant. The priority place in the rehabilitation of persons injured at work belongs to the sanatorium-resort treatment (ST). Among the measures for the rehabilitation of persons with OD in Tatarstan, 94\% are in ST, 5\% are technical means of rehabilitation (most often it is hearing aids).

In the structure of expenditures of the Social Insurance Fund in the first place - payment of compensation for lost earnings (87 - $90 \%$ of funds). $10-13 \%$ is spent on the implementation of preventive measures and rehabilitation. In the Republic of Tatarstan, the share of expenses for rehabilitation is $18-20 \%$, insurance pay- ments - $80-82 \%$, respectively. The specific weight of the expenses for the ST of the injured at work (of the industrial injuries and occupational diseases) is currently up to $57 \%$ of the cost of rehabilitation.

With OD, rehabilitation at the expense of the Social Insurance Fund is currently carried out in the presence of persistent disability (moderate and pronounced manifestations of OD) after the conclusion of the MSE. Identification of the initial signs of OD and early rehabilitation of workers should help to reduce the cost of insurance benefits. Sanatorium-resort treatment is used in programs for early rehabilitation of persons affected by severe industrial injuries, implemented immediately after the onset of industrial injuries (comprehensive rehabilitation of injured at work of severe accident at work) [3]. In the Republic of Tatarstan, within the framework of this project, the costs of ST account for up to $44 \%$ of the funds spent on early rehabilitation. In 2015, during the implementation of the this project, $40 \%$ of the number of severe accidents at work ended in full recovery and restoration of working capacity; 2016 - 44\%. In 2017, an increase in this indicator was recorded: $53 \%$ of those with industrial injuries who completed treatment, fully restored their ability to work (to the data of the Social Insurance Fund). In 2018, the proportion of the patients injured at work with the restoration of working capacity was $46.1 \%$. Further, there is an increase in this indicator by more than $70 \%$.

\section{Conclusion}

- In Russian Federation, a system has been created for the rehabilitation of persons who have occupational diseases or who have received an industrial injury.

- In connection with the need for compensation payments, disability due to occupational diseases and accidents at work is of great social importance. Among occupational diseases, diseases of the respiratory system are more limited the ability to work.

- The priority place in the rehabilitation of persons injured at work belongs to the sanatorium-resort treatment.

- The program of early comprehensive rehabilitation of persons affected by severe accidents at work, implemented immediately after the onset of industrial injury, contributes to the restoration of the working capacity of the majority of such workers. 
- The rehabilitation system for occupational diseases is currently being implemented at the stage of prevention of disease progression and further decline in working capacity, that is, secondary prevention of disability.

For further optimization of the expert and rehabilitation section of the work on medical care for persons injured at work, it is advisable to make appropriate changes to the existing regulatory documents and consolidate the priority of preventive measures to prevent occupational diseases and accidents at work in the distribution of social insurance funds. Improving the quality of medical support for workers have contact with hazardous industrial factors and patients with occupational diseases will help prevent disability due to occupational diseases and save social insurance funds.

\section{Conflict of Interest}

No exists any financial interest or any conflict of interest.

\section{Bibliography}

1. Artamonova VG., et al. "The evaluation of occupational patients of the construction materials industry". Herald of the Mechnikov Saint-Petersburg State Medical Academy 4.29 (2008): 64-67.

2. Lobanov S N and Khanchenkov NS. "On the economic efficiency of treatment and rehabilitation of insured persons immediately after severe accidents at work". Medicine In Kuzbass 4.3 (2004): 3-7.

3. Pederko IG., et al. "Expertise of working capacity in trauma of the peripheral nervous system". Associations of Neurosurgeons 6 (1998): 36-41.

4. Sidorkina LA. "Formation of a rehabilitation system for persons who have suffered health damage as a result of an industrial accident or occupational disease". Restorative Medicine and Rehabilitation. Proceedings of the First International Congress (2004): 290-291.

5. Skvirskaya GP and Seregina IF "Medical and social rehabilitation of workers and persons injured at Work". Restorative Medicine and Rehabilitation. Proceedings of the First International Congress (2004): 292-293.
6. Shestakov VP and Svintsov AA. "Problems of improvement of evaluation and control of quality of medical-social rehabilitation of the disabled". Herald of the Mechnikov Saint-Petersburg State Medical Academy. 2.31 (2009): 17-22.

\section{Volume 5 Issue 7 July 2021}

(C) All rights are reserved by Ishteryakova Olga

Alexandrovna., et al. 